ORIGINAL ARTICLE

\title{
Video analysis of injuries and incidents in Norwegian professional football
}

\author{
T E Andersen, A Tenga, L Engebretsen, R Bahr
}

Br J Sports Med 2004;38:626-631. doi: 10.1136/bjsm.2003.007955

See end of article for authors' affiliations

.....................

Correspondence to:

Dr Thor Einar Andersen,

Oslo Sports Trauma

Research Center,

Norwegian University of

Sport and Physical

Education, PO Box 4014,

Ullevål Stadion, Oslo

0806, Norway; thor.einar.

andersen@nih.no

Received

26 September 2003

Accepted for publication

28 September 2003

\begin{abstract}
Objectives: This study describes the characteristics of injuries and high risk situations in the Norwegian professional football league during one competitive season using Football Incident Analysis (FIA), a video based method.

Methods: Videotapes and injury information were collected prospectively for 174 of $182(96 \%)$ regular league matches during the 2000 season. Incidents where the match was interrupted due to an assumed injury were analysed using FIA to examine the characteristics of the playing situation causing the incident. Club medical staff prospectively recorded all acute injuries on a specific injury questionnaire. Each incident identified on the videotapes was cross referenced with the injury report.

Results: During the 174 matches, 425 incidents were recorded and 121 acute injuries were reported. Of these 121 injuries, 52 (43\%) were identified on video including all head injuries, $58 \%$ of knee injuries, $56 \%$ of ankle injuries, and $29 \%$ of thigh injuries. Strikers were more susceptible to injury than other players and although most of the incidents and injuries resulted from duels, no single classic injury situation typical for football injuries or incidents could be recognised. However, in most cases the exposed player seemed to be unaware of the opponent challenging him for ball possession.

Conclusions: This study shows that in spite of a thorough video analysis less than half of the injuries are identified on video. It is difficult to identify typical patterns in the playing events leading to incidents and injuries, but players seemed to be unaware of the opponent challenging them for ball possession.
\end{abstract}

F ootball is a complex contact sport with high physical, technical, tactical, and physiological demands at the elite level, ${ }^{12}$ and the risk of injury is considerable. Although differences in study design and injury definitions make a direct comparison between studies difficult, the incidence of injuries among adult male players has been estimated to be between 10 and 35 per 1000 game hours. $^{34}$

While a considerable number of studies have described the incidence and injury pattern (injury type, localisation, and severity) in football, ${ }^{34}$ much less is known about risk factors $^{35-8}$ or injury mechanisms. ${ }^{9-15}$ The majority of the injuries are thought to be unintentional, resulting from chance or an error by the player injured or another player. ${ }^{16}$ Hence, it is not surprising that only seven studies that have developed and tested injury prevention programs in football have been published to date. ${ }^{15}{ }^{17-22}$ Although these studies show promising effects of various generic interventions, prevention programs specific to the sport of football have not yet been developed. More sport-specific information is necessary to develop preventive measures targeting the injury mechanisms involved in football.

Based on player interviews, contact injuries have been found to represent $40-74 \%$ of all acute injuries, ${ }^{9-11} 23$ mainly resulting from tackling duels. ${ }^{9-11}{ }^{23}$ Thus, receiving or making a tackle is thought to involve a substantial injury risk. Contact injury resulting in head injuries has received little attention in the literature. ${ }^{24}$ The most common injury mechanism among elite football players is believed to be head-to-head contact, followed by head-to-ground and headto-other body parts, for example, foot, knee, or elbow, or being hit in the head by the ball from close range. ${ }^{14} 25$ Noncontact injury mechanisms are thought to account for about half of all acute injuries, with sprinting, shooting, or kicking being the most frequent causes reported. ${ }^{91123}$ However, in most studies the information on injury mechanisms has been collected retrospectively from either the player involved ${ }^{9-15} 2326$ or the team physician. ${ }^{27}$ This approach is difficult due to recall bias by either the team physician or the injured player, and since injuries happen quickly, often in complex situations, the description may be incorrect.

Most elite football matches are televised, so using video recordings instead of post-injury player interviews can improve our ability to more objectively identify and understand the injury mechanisms. However, since football is a complex game, it is not easily described in quantitative terms, whether attempting to analyse the flow of the game, playerto-player interactions, or goal scoring opportunities, or to describe injury situations. Nevertheless, video analysis represents an opportunity to analyse and describe the events typically leading up to an injury situation in football-specific terms. Hawkins and Fuller ${ }^{28}$ analysed video recordings from 44 of 52 matches in the 1994 World Championship and 181 matches at three levels of professional football in England. They found that between 15\% and 29\% of incidents resulted from foul play. However, their analysis was limited to the effect of foul play on injury risk, and they had limited access to medical information from the incidents described. Furthermore, Rahnama et $a l^{29}$ assessed the exposure of players to playing actions during English Premier League matches and found that more than one third of the playing actions were judged to have some level of injury potential (assessed subjectively on the likelihood of the actions to produce an injury). Unfortunately, a more detailed description of the characteristics of high-risk playing actions was not provided.

Match analysis has been widely used for some time among football coaches worldwide, ${ }^{30}{ }^{31}$ and more refined computerassisted methods based on video recordings have recently been developed..$^{32}{ }^{33}$ A better understanding of the injury mechanisms and the events leading up to high-risk situations

Abbreviations: FIA, Football Incident Analysis; RR, relative risk 


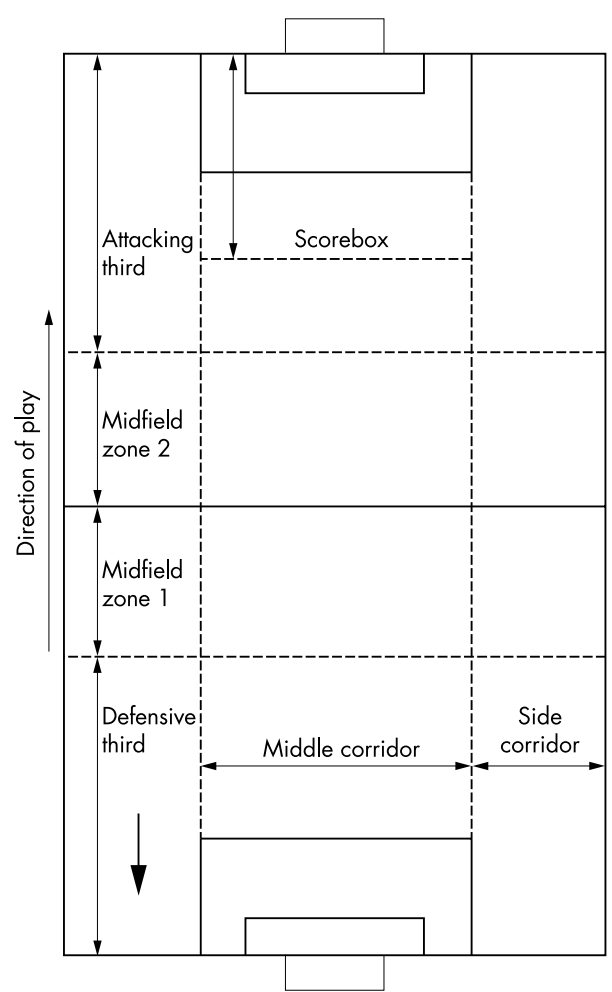

Figure 1 Zones of the playing field. The defensive zone is defined as the defending third of the field, midfield zone 1 is the first half of the middle third, and midfield zone 2 is the second half of the middle third. The attacking zone is the attacking third and the scorebox is the zone between the prolongation of the short sides of the penalty area until the half way line between the $16 \mathrm{~m}$ line and the line dividing the attacking and middle thirds. The side corridor is one third of the width of the field on each side of the middle corridor.

is essential in order to design future prevention programs. Football incident analysis (FIA) ${ }^{34}$ is a video-based method that combines football-specific and medical information to describe how injuries and high-risk situations of injury occur. Thus, the purpose of this study was to describe the characteristics of injuries and high-risk situations in the Norwegian professional football league during one competitive season using FIA.

\section{METHODS}

Videotapes and injury information were collected prospectively for the regular league matches during the 2000 Norwegian season (April through October). The regular league is a double round robin competition with home and away matches between 14 teams, resulting in a total of 182 matches.

The Norwegian Broadcasting Cooperation (NRK) and TV2 Norway secured a weekly delivery of DVC pro and Beta SP quality video cassettes from 174 of the 182 matches (96\%). Regional TV-production teams with one to three cameras were responsible for most of the recordings; 20 matches were live broadcasts with six cameras, including two high-speed slow-motion cameras. Of the 174 videotapes, 157 covered the match in full, while the remaining 17 covered $73 \mathrm{~min}$ on average (range: $36-87 \mathrm{~min}$ ). The total duration of the video recordings was $15367 \mathrm{~min}$, which corresponds to $256 \mathrm{~h}$ of football. The total playing time not covered by video tapes was 283 min which corresponds to $2 \%$ of the matches covered by this study.

The videotapes were reviewed by one physician (TEA) and one expert on football match analysis (AT). All situations where the match was interrupted by the referee, one or more players lay down on the pitch for more than $15 \mathrm{~s}$, and the player(s) appeared to be in pain or received medical treatment, were noted as an incident. The $15 \mathrm{~s}$ was chosen because that was thought to be long enough to avoid situations where players intentionally lay down either to rest or to delay playing time. These incidents, including the entire play leading up to each of them, were transferred to a master videotape.

\section{FIA}

The incidents on the master videotape were analysed using FIA, a video-based method allowing incidents to be described using 19 variables, each with two or more categories, which have been described in detail in a previous report. ${ }^{34}$ This analysis describes each incident related to the: (1) injured player (for example, playing position, action with the ball, movement direction and intensity); (2) injured team (for example, type of relational skill, including all types of passes); (3) opposing team (for example, degree of defensive team balance); (4) match (for example, match type, match time, playing phase); (5) attacking play (for example, attack type, attacking effectiveness); (6) defensive play (for example, duel type, tackling type, ball winning); (7) playing field (for example, location; fig 1); and (8) foul play (for example, foul type, referee's decision).

\section{Injury records}

Club medical staff, physiotherapists, and/or physicians for all 14 first league clubs prospectively recorded all acute injuries that occurred during regular league matches. An injury was recorded if the player was unable to participate in training or match play for at least 1 day following the incident. ${ }^{35}$ Injuries were classified as minor when the player could not fully participate in training or matches for 1-7 days, moderate if absent for 8-21 days, and serious if absent for more than 21 days. ${ }^{3}$

All players (about 330) with an A-squad contract who participated in matches were covered by the injury registration. A specific injury questionnaire was used and reports were collected on a monthly basis.

The form included information on the date of injury and during which match the injury occurred, as well as the time of injury. Furthermore, the playing position and the injury location were registered and injuries were classified as

Table 1 Number of injuries classified according to body location in males playing 174 Norwegian professional football matches during the 2000 season

\begin{tabular}{lccc}
\hline & $\begin{array}{l}\text { Injuries } \\
\text { identified } \\
\text { on video }\end{array}$ & $\begin{array}{l}\text { Injuries not } \\
\text { identified } \\
\text { on video }\end{array}$ & Total \\
\hline Head & 9 & 0 & 9 \\
Cervical spine/neck & 1 & 1 & 2 \\
Shoulder incl. clavicle & 0 & 1 & 1 \\
Elbow & 0 & 1 & 1 \\
Trunk & 1 & 1 & 2 \\
Abdomen & 0 & 1 & 1 \\
Thoracic/lumbar spine & 2 & 4 & 6 \\
Groin & 0 & 7 & 7 \\
Hip & 1 & 1 & 2 \\
Thigh & 9 & 22 & 31 \\
Knee & 11 & 8 & 19 \\
Lower leg & 6 & 9 & 15 \\
Ankle & 10 & 8 & 18 \\
Foot/toes & 2 & 5 & 7 \\
Total & 52 & 69 & 121 \\
\hline The columns show the injuries identified on video ( $n=52)$, injuries not \\
identified on video $(n=69)$, and the total number of injuries $(n=121)$. \\
\hline
\end{tabular}




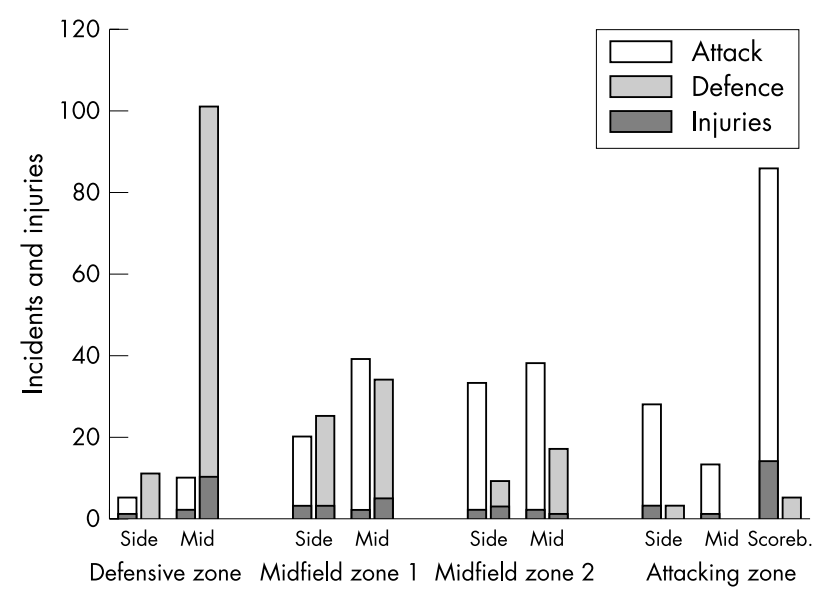

Figure 2 Number of incidents $(n=425)$ and injuries $(n=52)$ in the different zones of the field during the attacking and defending playing phases. Scoreb., scorebox.

contusions, sprains, strains, fractures, or lacerations. Finally, each injury received a specific diagnosis using Orchard codes. ${ }^{36}$

Each incident identified on the videotapes was crossreferenced with the injury reports. In addition, the original tapes were re-examined to find incidents which had not been identified in the first video review. Although the injury reports included information on which match and what time during the match each injury occurred, we were only able to identify an additional four injuries during the second video review. However, these four did not fit with the definition of an incident.

\section{Statistical analysis}

Injury and incident rates were recorded as the number per 1000 player hours. The relative risk (RR) for injuries and incidents for specific playing positions was estimated as the ratio between incidents and injuries sustained to the number of players in the formation normally used by each team. Ten teams played a 4:3:3, three teams a 4:4:2, and one team a 4:1:2:1:2 formation. This means that the formation used to calculate RR consisted of one goalkeeper, two fullbacks, two central defenders, two wing midfielders, 1.3 central midfielders, 1.4 inside midfielders, and 1.3 strikers. Injury severity was compared between injuries observed on video and those not identified on video using chi-squared statistics. A chi-squared test with $5 \mathrm{df}$ was used to test for equality of incidents and injuries between the six 15 min periods of the match.

\section{RESULTS}

\section{Incidents and injuries}

During the 174 matches available for video analysis, 425 incidents were recorded, that is, 1.2 incidents per team per match or 75.5 incidents per 1000 player hours. A total of 121 acute injuries were reported from the same matches, that is, 0.3 injuries per team per match or 21.5 injuries per 1000 player hours. Injuries and incidents were distributed evenly throughout the six 15 min periods of the matches (incidents: $\chi^{2}=5.4 ; p>0.10$; injuries: $\chi^{2}=2.1 ; p>0.10$, both NS).

Of the 121 acute injuries reported to have occurred during the matches by the club medical staff, 52 (43\%) were identified on video. Of these, $18(35 \%)$ were classified as serious, $16(31 \%)$ as moderate, and $18(35 \%)$ as minor injuries. Of the 69 injuries not identified on video, 14 (20\%) were classified as serious, $20(29 \%)$ as moderate, and 35 $(51 \%)$ as minor $(\mathrm{p}=0.18 v$ injuries identified on video,

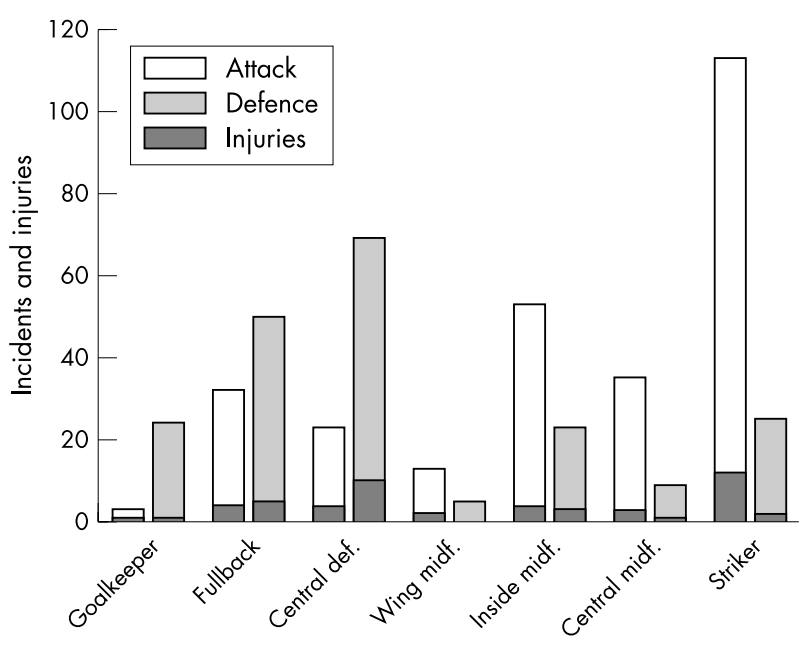

Figure 3 Number of incidents $(n=425)$ and injuries $(n=52)$ classified according to player position, that is, the static positions of players on the field based on playing formations. def., defender; midf., midfielder.

chi-squared test). Some $75 \%$ of the injuries affected the lower extremities. All the head injuries, $58 \%$ of the knee injuries, $56 \%$ of the ankle injuries, $29 \%$ of the thigh injuries, $40 \%$ of the lower leg injuries, and none of the groin injuries were identified on the videotapes (table 1). Of the nine head injuries, there were three concussions, three facial fractures, and three lacerations. Of the 22 thigh injuries not identified on video, 18 were muscle strains (table 1).

\section{FIA}

Of the 425 incidents recorded, 242 occurred when the teams were in the attacking phase (30 injuries) and 183 in the defending phase (22 injuries). A significant portion of the defensive incidents $(91,50 \%)$ and injuries $(10,45 \%)$ occurred in the mid-defensive zone, while many of the offensive incidents $(72,30 \%)$ and injuries $(14,47 \%)$ took place in the score-box (fig 2).

Strikers were exposed to 124 incidents $(30 \% ; \mathrm{RR}=2.5)$ and involved in 14 injuries $(27 \%, \mathrm{RR}=2.3)$. The corresponding figures for central defenders were 78 incidents (18\%; $\mathrm{RR}=1.0)$ and 14 injuries $(27 \%, \mathrm{RR}=1.5)$, fullbacks 73 incidents $(17 \%$; $R R=0.9)$ and nine injuries $(17 \%, R R=0.9)$, and inside midfielders 69 incidents $(16 \%$; $R R=1.3)$ and

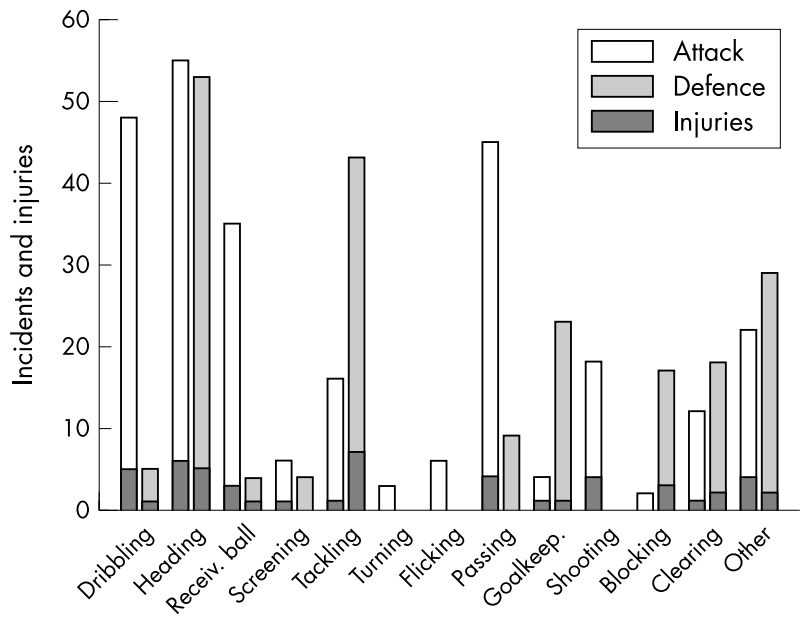

Figure 4 Number of incidents $(n=425)$ and injuries $(n=52)$ classified according to type of individual action with the ball. Goalkeep., goalkeeping; Receiv., receiving. 
seven injuries $(13 \%, \mathrm{RR}=1.1)$. Wing midfielders with 16 incidents $(\mathrm{RR}=0.2)$ and two injuries $(\mathrm{RR}=0.2)$ and goalkeepers with 25 incidents $(\mathrm{RR}=0.6)$ and two injuries $(R R=0.4)$ were less prone to incidents and injuries (fig 3 ). Strikers and midfielders were more prone to incidents and injuries in the offensive playing phase, whereas defenders and goalkeepers were more susceptible when defending.

In the defending phase the most common categories of individual action with the ball that resulted in incidents were tackling (20\%, injuries: $32 \%)$, heading (26\%, injuries: $23 \%)$, blocking and clearance (16\%, injuries: $23 \%$ ), and goalkeeping ( $12 \%$, injuries: $5 \%)$. In the offensive phase heading $(20 \%$, injuries: $20 \%)$, dribbling (18\%, injuries: $17 \%)$, shooting $(6 \%$, injuries: 13\%), and passing the ball (17\%, injuries: 13\%) caused most incidents and injuries (fig 4).

A short pass was the most common team event prior to incidents (49\%) and injuries (48\%), and this trend was the same for the defending and attacking playing phases (fig 5). Incidents and injuries after short passes were evenly distributed between the different playing positions, whereas strikers, central defenders, fullbacks, and goalkeepers were involved in more incidents after long forward passes compared to the other playing positions.

Of 242 offensive incidents (30 injuries), the level of ball control was low in 140 (17) cases, while the involved player had complete ball control in 102 (13) cases. Of the 183 defensive incidents (22 injuries), the level of ball control was low in 165 (21) cases, whereas the involved player had complete control of the ball in 18 (one) cases.

The opposing team was in good defensive balance at the time of the incident in 183 of the offensive incidents (17 injuries), while the opponent team balance was moderate in 45 cases (nine injuries) and poor in 14 cases (four injuries). The intensity of play was high in 175 of the offensive incidents (23 injuries) and low in 67 cases (seven injuries). Of the defensive incidents the intensity was high in 109 (14 injuries) and low in 74 cases (eight injuries).

Most incidents and injuries resulted from duels, primarily tackling duels with 194 incidents (46\%) and 25 injuries (48\%; fig 6A). Heading duels resulted in 91 incidents $(21 \%)$ and eight injuries $(15 \%)$. Being tackled from the side was the main cause of tackling incidents (20\%) and injuries (23\%; fig $6 \mathrm{~B}$ ). Player to player contact occurred in $90 \%$ of the 52 injuries observed on video.

Of the 242 offensive incidents (30 injuries), the exposed player appeared to be unaware of the opposing player in 238 cases (30 injuries). In other words, in only four $(2 \%)$ of the

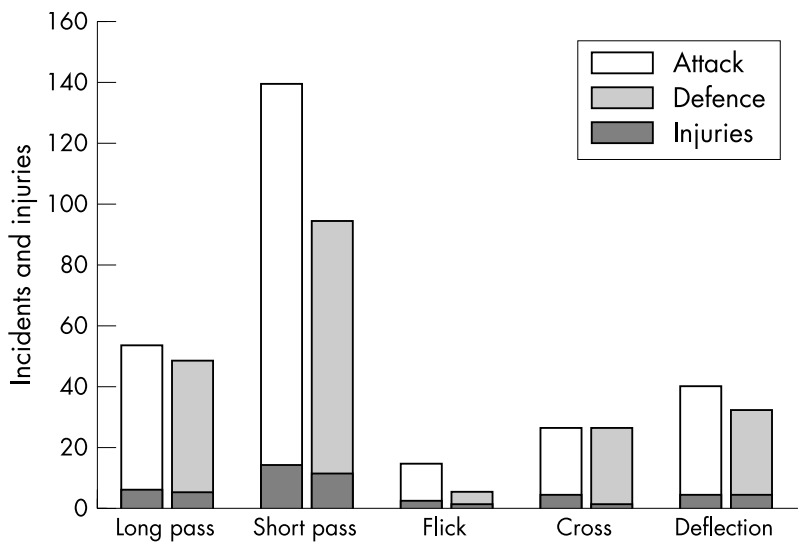

Figure 5 Number of incidents $(n=425)$ and injuries $(n=52)$ classified according to last team action, that is, type of passing actions by the attacking team prior to incident or injury.

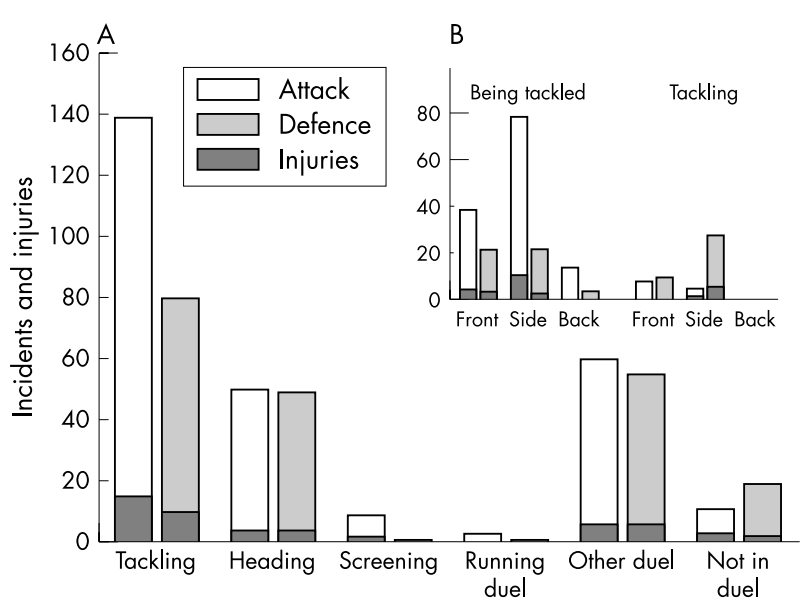

Figure 6 (A) Number of incidents $(n=425)$ and injuries $(n=52)$

classified according to type of duel. (B) Number of incidents $(n=425)$ and injuries $(n=52)$ classified according to type of tackling.

incidents and none of the injuries was the attention of the exposed player directed towards his primary duellist (fig 7).

\section{DISCUSSION}

The aim of the present study was to describe the events leading to football injuries and incidents in the Norwegian professional league during one competitive season using a new video-based method, FIA. ${ }^{34}$ An unexpected finding was that, although we performed a thorough review of the tapes, we were able to identify less than half of the acute injuries reported to have occurred during the same matches by the club medical staff. Secondly, although the majority of the incidents were tackling and heading duels it was difficult to detect any obvious patterns in the playing actions leading to incidents and injuries. Nevertheless, some common trends were discernible: (1) strikers appeared to be at greater risk than other players, (2) most incidents took place in the middefensive zone and in the scorebox in the attacking zone, and (3) in almost all cases the attention of the exposed player was not directed at the opponent causing the incident.

We were somewhat surprised to see that less than half of the injuries reported by the club medical staff to have led to subsequent absence from training or competition were identified on the videos. Of the three most common injury types-thigh, ankle, and knee-only $58 \%$ of the knee injuries, $56 \%$ of the ankle injuries, $29 \%$ of the thigh injuries,

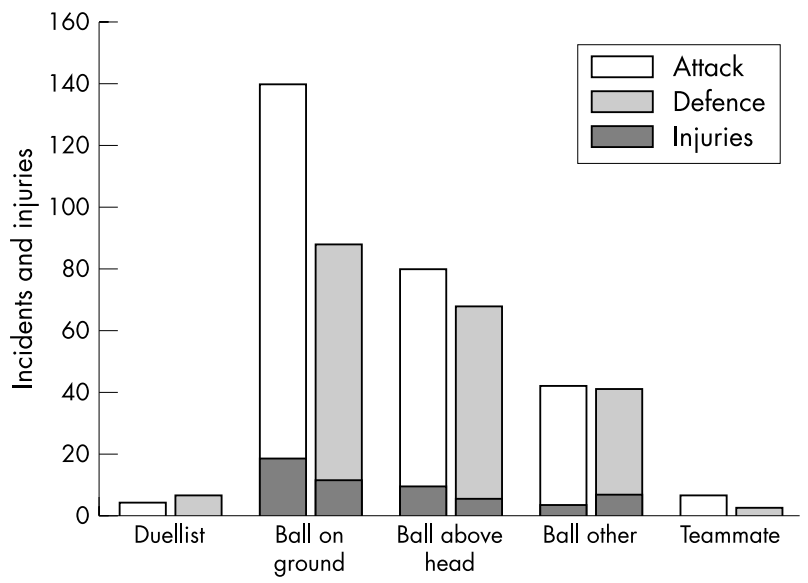

Figure 7 Number of incidents $(n=425)$ and injuries $(n=52)$ classified according to where the attention of the player appeared to be directed. 
and none of the groin injuries were identified on video. Of the 22 thigh injuries not identified on the video, 18 were hamstring strains. This means that the majority of the hamstrings strains and a significant proportion of the knee and ankle injuries were not recognised as an incident, that is, there was no stoppage in play and the player did not go down on the pitch. The player was able to continue, and was not given treatment until halftime and was then substituted or was not treated until after the match.

These results imply that a video analysis alone, as previously used in the studies of Hawkins and Fuller ${ }^{28} 37$ and Rahnama et al, ${ }^{29}$ without simultaneous access to medical information from team medical staff may result in a biased description of how football injuries occur. Such an approach can be expected to reveal the more spectacular incidents resulting from player-to-player contact, but may overlook a significant number of injuries, in particular muscle strains to the thigh, groin, and lower leg, but also a number of ankle and knee sprains. In contrast, all of the head injuries were identified. Although severity was similar between injuries identified on video and those not identified, an analysis based on video tapes alone could be biased towards certain injury types or injury mechanisms, for example, contact injuries resulting from duels. Other injury types, for example, hamstrings strains, would be gravely underestimated, since only one-third were identified on the video tapes in the present study.

From a prevention point of view, it is disappointing that, in spite of a thorough classification of more than 400 incidents (and 52 injuries), it was not possible to identify any characteristic situations that could account for a significant proportion of the injuries in football, as has been done for ankle injuries in volley ball ${ }^{38}$ and ACL injuries in skiing ${ }^{39}$ and female team handball. ${ }^{40}{ }^{41}$ This is perhaps not surprising, since football is a complex sport with few fixed plays, few specialised skills, and countless potential player-to-player interactions. Rahnama et al, using a slightly different approach to ours, assessed the exposure of players to injury risk during ten English Premier League matches and found that a very large number of situations during football matches have some injury potential. ${ }^{29}$ However, it should be noted that the approach used in both their and the present study was to look for patterns in the playing situations leading to incidents, since such patterns could potentially be used to develop preventive strategies. We have not examined the mechanisms of injuries in conventional biomechanical terms, nor were we able to look at specific injury types, for example, hamstring, knee, and ankle injuries, since the number of videos available for each of these was limited. Thus, we can not rule out that specific injury mechanisms may be involved for each of these types of injury. Although this was beyond the scope of the present study, a systematic analysis of the mechanisms causing these injury types might reveal patterns that could be used in injury prevention.

However, although no typical injury situations could be recognised, we observed some trends among the incidents and injuries identified on video. One was that strikers appeared to be at greater risk than others, another that more incidents took place in the mid-defensive zone and the scorebox. The literature on player function and injury risk is contradictory, with an early study supporting our finding that strikers are most likely to sustain an injury, ${ }^{42}$ while most previous studies have concluded that player position does not seem to influence the injury rate. ${ }^{4}$ Two recent studies have suggested that defenders ${ }^{28}$ and midfield players ${ }^{34}$ were the field positions with the greatest risk of injury. The apparent discrepancy between studies could reflect different playing styles between countries and different levels of play. However, it seems clear that it is not sufficient to focus on one or a few player categories to effectively prevent injuries in football.

Another trend was that, of the incidents and injuries identified on the videos, $90 \%$ resulted from player-to-player contact in duels, half of them from tackling duels (mainly from the side) and 15\% from heading duels (fig 6). These results correspond both with the observations of Rahnama et $a l,{ }^{29}$ who found that all major injuries (that is, where the player received treatment and left the field for the remainder of the game) occurred from receiving a tackle, and with the questionnaire study in Finnish elite football by Lüthje et al. ${ }^{10}$ However, it is important to keep in mind that more than half of our injuries were not identified on the video tapes. A similar bias can be expected in the study by Rahnama et al, ${ }^{29}$ and their conclusion that the majority of injuries were linked to contesting possession may for that reason be flawed. Although the mechanisms for injuries not seen on tape are unknown, it appears less likely that they resulted from duels, since they did not result in a player going down on the pitch. As mentioned above, video analysis is likely to overestimate the percentage of acute injuries resulting from duels, unless medical information is available from the same matches. This suggestion is corroborated by other studies based on player and medical staff reports, showing that about half of all acute injuries were contact injuries. ${ }^{12} 23$

Perhaps the most promising finding from a prevention point of view was the analysis of where the attention of the injured player appeared to be focused. It must be acknowledged that evaluating player attention based on the video pictures can be difficult in some cases. However, based on our subjective judgement the attention of the injured player was directed towards his primary duellist in only $2 \%$ of the cases. It appears that in most cases the players were fully concentrated on the ball and did not have the overview that may be necessary to evade an opponent contesting possession and avoid injury. It may be hypothesised that injuries can be prevented by getting coaches and players to focus on this aspect during training to try to increase their functional field of vision and be more conscious of the actions of opponents and team mates.

Improved ball-handling skills would also reduce the need to focus on the ball at all times during play. On the basis of the findings in this study, the coaches may be advised to focus on technical skills for different playing positions, especially the first touch. Furthermore, they should focus on improving the players' functional field of vision and awareness of opponents and team-mates in their immediate vicinity.

Along the same lines, it may be possible to prevent injuries by raising the awareness of potential injury situations among players. Computer-based tools for match analysis are widely used by coaches, and they provide important information on each player's movements and ball involvements during a match. $^{32}{ }^{33}$ Video sessions are routinely used, at least in professional teams, to improve player and team performance. A similar approach could be tested to avoid injury. A player and the coach and/or a member of the medical staff could review video-recordings of duels and other actions by the player to identify situations during a match with a potential for injury and develop strategies to minimise risk.

\section{CONCLUSIONS}

This study shows that less than half of the acute time-loss injuries that were reported by club medical staff to have occurred during football matches were identified through a thorough review of video tapes from the same matches. Furthermore, the majority of the injury risk incidents occurred during tackling and heading duels. Although an extensive video analysis did not reveal one typical injury 


\section{What is already known}

In football the risk of injury is considerable. Although a large number of studies have described the incidence and injury pattern (injury type, localisation, and severity), very little is known about the injury mechanisms. The majority of the injuries are thought to be unintentional, mainly resulting from tackling duels.

\section{What this study adds}

Less than half of the injuries that occurred during matches were identified through video analysis indicating that many football injuries result from non-contact mechanisms. No single specific playing situation was recognised as typical for football injuries. However, it may be possible to prevent injuries by teaching players improved awareness of opponents challenging them for ball possession.

situation or pattern characteristic of the events leading to incidents and injuries, some trends were observed. Strikers appeared to be at greater risk than others and more incidents took place in the mid-defensive zone or the scorebox. In almost all cases the attention of the player appeared to be focusing on the ball and directed away from the opponent challenging them for ball possession.

\section{Authors' affiliations}

T E Andersen, A Tenga, L Engebretsen, R Bahr, Oslo Sports Trauma Research Center, Norwegian University of Sport and Physical Education, Ullevål Stadion, Oslo, Norway

Conflict of interest: none declared.

\section{REFERENCES}

1 Ekblom B. Applied physiology of soccer. Sports Med 1986;3:50-60.

2 Reilly T. The physiological demands of soccer. In: Bangsbo J, ed. Soccer and science: in an interdisciplinary perspective. Copenhagen: Munksgaard, 2000:91-105.

3 Inklaar H. Soccer injuries. I: Incidence and severity. Sports Med 1994; 18:55-73.

4 Dvorak J, Junge A. Football injuries and physical symptoms. A review of the literature. Am J Sports Med 2000;28:S3-9.

5 Schmidt-Olsen S, Jörgensen U, Kaalund S, et al. Injuries among young soccer players. Am J Sports Med 1991;19:273-5.

6 Ekstrand J, Gillquist J, Möller M, et al. Incidence of soccer injuries and their relation to training and team success. Am J Sports Med 1983;1 1:63-7.

7 Nielsen $A B, Y$ de J. Epidemiology and traumatology of injuries in soccer. Am J Sports Med 1989;17:803-7.

8 Ekstrand J, Tropp H. The incidence of ankle sprains in soccer. Foot Ankle 1990;11:41-4.

9 Árnason Á, Gudmundsson A, Dahl HA, et al. Soccer injuries in Iceland. Scand J Med Sci Sports 1996;6:40-5.

10 Lüthje P, Nurmi I, Kataja M, et al. Epidemiology and traumatology of injuries in elite soccer: a prospective study in Finland. Scand J Med Sci Sports 1996;6:180-5.
11 Hawkins RD, Fuller CW. A prospective epidemiological study of injuries in four English professional football clubs. Br J Sports Med 1999;33:196-203.

12 Chomiak J, Junge A, Peterson L, et al. Severe injuries in football players: influencing factors. Am J Sports Med 2000;28:S-58-68.

13 Östenberg A, Roos H. Injury risk factors in female European football. A prospective study of 123 players during one season. Scand J Med Sci Sports 2000; 10:279-85

14 Boden BP, Kirkendall DT, Garrett WEJ. Concussion incidence in elite college soccer players. Am J Sports Med 1998;26:238-41.

15 Heidt RSJ, Sweeterman LM, Carlonas RL, et al. Avoidance of soccer injuries with preseason conditioning. Am J Sports Med 2000;28:659-62.

16 Reilly T. Science and football: an introduction. In: Reilly T, Clarys J, Murphy WJ, eds. Science and football II. London: E\&FN Spon, 1993:3-11.

17 Ekstrand J, Gillquist J, Liljedahl SO. Prevention of soccer injuries. Supervision by doctor and physiotherapist. Am J Sports Med 1983;11:116-20.

18 Surve I, Schwellnus MP, Noakes T, et al. A fivefold reduction in the incidence of recurrent ankle sprains in soccer players using the Sport-Stirrup orthosis. Am J Sports Med 1994;22:601-6.

19 Tropp H, Askling C, Gillquist J. Prevention of ankle sprains. Am J Sports Med 1985;13:259-62.

20 Caraffa A, Cerulli G, Projetti M, et al. Prevention of anterior cruciate ligament injuries in soccer. A prospective controlled study of proprioceptive training. Knee Surg Sports Traumatol Arthrosc 1996;4:19-21.

21 Söderman K, Werner S, Pietila T, et al. Balance board training: prevention of traumatic injuries of the lower extremities in female soccer players. A prospective randomized intervention study. Knee Surg Sports Traumatol Arthrosc 2000;8(6):356-63.

22 Junge $A$, Roesch D, Peterson $L$, et al. Prevention of soccer injuries: a prospective intervention study in youth amateur players. Am J Sports Med 2002;30:652-9.

23 Hawkins RD, Hulse MA, Wilkinson C, et al. The association football medical research programme: an audit of injuries in professional football. $\mathrm{Br} J$ Sports Med 2001;35:43-7.

24 Kirkendall DT, Jordan SE, Garrett WE. Heading and head injuries in soccer. Sports Med 2001;35(1):369-86.

25 Barnes BC, Cooper L, Kirkendall DT. Concussion history in elite male and female soccer players. Am J Sports Med 1998;26:433-8.

26 Ekstrand J, Gillquist J. Soccer injuries and their mechanisms: a prospective study. Med Sci Sports Exerc 1983;15:267-70.

27 Biordal JM, Arnly F, Hannestad B, et al. Epidemiology of anterior cruciate ligament injuries in soccer. Am J Sports Med 1997;25:341-5.

28 Hawkins RD, Fuller CW. Risk assessment in professional football: an examination of accidents and incidents in the 1994 World Cup finals. Br J Sports Med 1996;30:165-70.

29 Rahnama N, Reilly T, Lees A. Injury risk associated with playing actions during competitive soccer. Br J Sports Med 2002;36:354-9.

30 Reep C, Benjamin B. Skill and chance in association football. J R Stat Soc (Ser A) $1968 ; 131: 581-585$.

31 Franks I, McGarry T. The science of match analysis. In: Reilly T, ed. Science and soccer. London: E\&FN Spon, 1996:364-70.

32 Olsen E, Larsen $\varnothing$. Use of match analysis by coaches. In: Reilly T, Bangsbo J, Hughes M, eds. Football and science III. London: E\&FN Spon, 1997:209-20.

33 Hughes M. Notational analysis. In: Reilly T, ed. Science and soccer. Liverpool: E\&FN Spon, 1996:343-61.

34 Andersen TE, Larsen O, Tenga A, et al. Football incident analysis (FIA): a new video-based method to describe injury mechanisms in professional football. Br J Sports Med 2003;37:226-32.

35 Keller CS, Noyes FR, Buncher CR. The medical aspects of soccer injury epidemiology. Am J Sports Med 1987;15:230-7.

36 Orchard J. Orchard Sports Injury Classification System (OSICS). Sports Health 1993;11:39-41.

37 Hawkins RD, Fuller CW. An examination of the frequency and severity of injuries and incidents at three levels of professional football. Br J Sports Med 1998;32:326-32

38 Bahr R, Karslen R, Lian $\varnothing$, et al. Incidence and mechanisms of acute ankle inversion injuries in volleyball. Am J Sports Med 1994;22:595-600.

39 Ettlinger CF, Johnson RJ, Shealy JE. A method to help reduce the risk of serious knee sprains incurred in alpine skiing. Am J Sports Med 1995;23:531-7.

40 Myklebust G, Maehlum S, Holm I, et al. A prospective cohort study of anterior cruciate ligament injuries in elite Norwegian team handball. Scand J Med Sci Sports 1998;8:149-53.

41 Olsen OE, Myklebust G, Engebretsen L, et al. Injury mechanisms for $\mathrm{ACL}$ injuries in team handball-a systematic video analysis. Am J Sports Med, in press.

42 McMaster WC, Walter M. Injuries in soccer. Am J Sports Med 1978;6:354-7. 